\title{
The role of radial oxygen loss on the flux of arsenic and other elements in rice rhizosphere
}

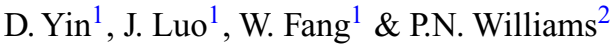 \\ ${ }^{1}$ State Key Laboratory of Pollution Control and Resource Reuse, School of the Environment, \\ Nanjing University, Jiangsu, P.R. China \\ ${ }^{2}$ Institute for Global Food Security, Queen's University Belfast, Belfast, UK
}

\begin{abstract}
In this study, we combined diffusive gradients in thin films (DGT) with planar optode (PO), a two-dimensional (2D) in situ chemical techniques for investigating the geochemical behaviors of arsenic in rice rhizosphere soil and bulk soil at high spatial resolution (sub-mm). We had observed three distinctive regions in rice rhizosphere: soil-water interfaces (SWI, $\mathrm{O}+$ ), rhizosphere aerobic soils $(\mathrm{O}+)$ and bulk anaerobic soils $(\mathrm{O}-)$. The mobility of arsenic and other elements is greater in rhizosphere than bulk zone, flux maxima for $\mathrm{As}, \mathrm{Fe}, \mathrm{P}, \mathrm{Pb}$ had also been observed around root tips. Our results indicate rice rhizosphere is a special unit to gather oxygen and affect metals mobility, both flux maxima for metals and radial oxygen loss from root tips are common existed in rice rhizosphere. We have provided new evidence for the importance of rhizosphere oxidation and coupled diffusion in modulating arsenic mobilization and dispersion, showing microniches are important geochemical phenomena exploited by rice plants to acquire metals or nutrients.
\end{abstract}

\section{INTRODUCTION}

Rhizosphere processes affect the fate of arsenic and other elements in rice rhizosphere. It is important and complicated for managing transformation of arsenic and other elements to plants. There exist complexity of root exudates and highly microbial communities in rhizosphere. (Lee et al., 2013) Williams et al. (2014) had developed a new sandwich sensor technology, consisting of a $\mathrm{pH} / \mathrm{O}_{2}$-sensitive planar optode, overlain by an ultrathin DGT layer for measuring As and other elements. We need a better understanding of micro/macroniches in trace elements uptake in rice. We still want to know whether those findings are common in other environment, such as higher level of arsenic or with other technologies.

\section{EXPERIMENTAL}

\subsection{Method summary}

An ultrathin DGT layer is exposed to the soil and backed by a planar optode as described in Williams et al. (2014). After rice was cultivated in the rhizotrons, the sandwich sensors were deployed in the rice rhizosphere. The DGT binding gel could record the locally induced As and other elements flux and the $\mathrm{O}_{2}$ planar optode can resolve the $\mathrm{O}_{2}$ concentration dynamics for the same location.

\subsection{Chemical mapping}

Three ultrathin DGT resin gel used in the sensors: suspended particulate reagent-iminodiacetate (SPR-IDA) (Warnken et al., 2004), precipitated ferrihydrite (PF) (Luo et al., 2010) and precipitated zirconia (PZ) (Guan et al., 2015). After deployed $24 \mathrm{~h}$ in the rhizotrons, the gels were retrieved and rinsed with MQ water, dried using a gel drier (Bio-Rad model 543) and then carefully fixed onto glass plates using double-sided adhesive tape prior laser ablation (LA) combined with ICP-MS analysis. ICP-MS was used to record ${ }^{13} \mathrm{C}$, ${ }^{75} \mathrm{As},{ }^{82} \mathrm{Se},{ }^{121} \mathrm{Sb},{ }^{31} \mathrm{P},{ }^{184} \mathrm{~W},{ }^{98} \mathrm{Mo},{ }^{57} \mathrm{Fe}$, and ${ }^{115} \mathrm{In}$ signals. Sampling soil and pore water when harvesting the plant using a compartmented design: soil-water interfaces, bulk anaerobic soils and rhizosphere aerobic soils. We used color ratiometric planar optode sensors to achieve oxygen images in the rhizotrons (Larsen et al., 2011).

\section{RESULTS AND DISCUSSION}

\subsection{As and other elements flux in rice rhizosphere}

Various location of $\mathrm{Fe}, \mathrm{As}, \mathrm{P}, \mathrm{Pb}, \mathrm{Mn}$ in different distance to rice roots. DGT-measured flux is determined by the concentration adjacent to the device surface, localized maxima in the DGT-flux reflect localized maxima in the elements concentration, indicating a 

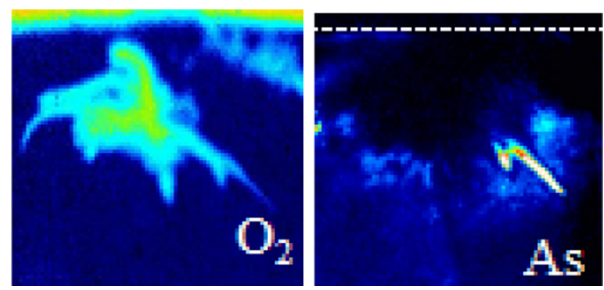

Figure 1. Visualization of $\mathrm{O} 2, \mathrm{Fe}, \mathrm{As}, \mathrm{P}, \mathrm{Pb}, \mathrm{Mn}$ around a set

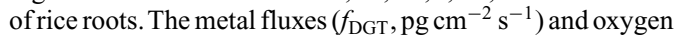
concentration (percent air saturation) increased sequentially with the color scale shown from blue to white.

localized process of mobilization (Williams et al., 2014). High-resolution imaging of DGT-measured elements flux around rice roots was conducted to obtain insight into the spatial variability of metals (Fig. 1). The oxygen images from rice rhizosphere and the corresponding elements fluxes from different SPRIDA DGT gel. As, $\mathrm{P}, \mathrm{Pb}$ and $\mathrm{Fe}$ (II) mobilization is low in where high oxygen around tap roots, which may due to Fe plaque promote these metals deposition onto root surfaces, resulting in decrease of metals availability. Wu et al. (2011) and Mei et al. (2009) had noted that there was a significant negatively correlation between ROL and As tolerance and accumulation in rice, which may be due to the effects of ROL on Fe plaque formation.

As and $\mathrm{V}, \mathrm{Mn}, \mathrm{Fe}, \mathrm{Co}, \mathrm{Cu}$ concentration in SWI are higher than the other two areas, may indicate that SWI could be a sink of these metals. This could be because the redox potential changes over soil depth under submerged condition, as a consequence of elements transport and accumulate in SWI. As accumulation in the topsoil relates to freshly precipitated $\mathrm{Fe} / \mathrm{Mn}$ oxides. This oxidized layer acted as a sink for As, Fe, Mn, V, $\mathrm{Co}, \mathrm{Cu}$ and might explain the depletion occurred in soil pore water monitored as revealed by the samplers located at the soil-water interface.

\subsection{Consistency of As with $P$ and $F e$}

As mobilization was consistent with $\mathrm{P}$ and $\mathrm{Fe}$, there are flux maximum exist in SWI and root apexes. As and $\mathrm{P}$ belong to the same chemical group and have comparable dissociation constants for their acids and solubility products for their salts, resulting in physicochemical similarity in soil. (Adriano, 2001) It is not surprising for the co-occurrence of As and Fe flux maxima. Arsenic is readily retained on Fe oxides, and their release often coincides. Meanwhile, with the redox threshold for the $\mathrm{Fe}(\mathrm{III}) / \mathrm{Fe}$ (II) transition lying close to the arsenate/arsenite boundary, the transformation to arsenite would favor a more rapid and extensive desorption. (Takahashi et al., 2004).

\section{CONCLUSIONS}

There is similar transport of As, $\mathrm{Zn}$ and Mn across the root plaque, but the location of the sub-surface resupply is well defined. Clearly the root apexes act as a sink for As, $\mathrm{Fe}(\mathrm{II}), \mathrm{V}, \mathrm{Mn}, \mathrm{Co}, \mathrm{Cu}$, metal remobilized in the tips of root and at the surface of water-soil. Flux maxima for As and some other elements are quite common, but not all roots will show this phenomenon.

\section{ACKNOWLEDGEMENTS}

This work was funded by the National Natural Science Foundation of China (NSFC) (No. 41771271 and 21477053), the NSFC and Newton Fund/Royal Society (No. 21511130063 and R1504GFS).

\section{REFERENCES}

Adriano, D.C. 2001. Arsenic. In: Trace Elements in Terrestrial Environments. Springer, New York, 219-261.

Guan, D.X., Williams, P.N., Luo, J., Zheng, J.L., Xu, H.C., Cai, C. \& Ma, L.Q. 2015. Novel precipitated zirconiabased DGT technique for high-resolution imaging of oxyanions in waters and sediments. Environ. Sci. Technol. 49(6): 3653-3661.

Larsen, M., Borisov, S.M., Grunwald, B., Klimant, I. \& Glud, R.N. 2011. A simple and inexpensive high resolution color ratiometric planar optode imaging approach: application to oxygen and pH sensing. Limnol. Oceanogr. Meth. 9(9): 348-360.

Lee, Y.J., Mynampati, K., Drautz, D., Arumugam, K., Williams, R. \& Schuster, S. 2013. Understanding aquatic rhizosphere processes through metabolomics and metagenomics approach. EGU General Assembly, 15.

Luo, J., Zhang, H., Santner, J. \& Davison, W. 2010. Performance characteristics of diffusive gradients in thin films equipped with a binding gel layer containing precipitated ferrihydrite for measuring arsenic (V), selenium (VI), vanadium (V), and antimony (V). Anal. Chem. 82(21): 8903-8909.

Mei, X.Q., Ye, Z.H. \& Wong, M.H. 2009. The relationship of root porosity and radial oxygen loss on arsenic tolerance and uptake in rice grains and straw. Environ. Pollut. 157(8): 2550-2557.

Takahashi, Y., Minamikawa, R., Hattori, K.H., Kurishima, K., Kihou, N. \& Yuita, K. 2004. Arsenic behavior in paddy fields during the cycle of flooded and non-flooded periods. Environ. Sci. Technol. 38(4): 1038-1044.

Warnken, K.W., Zhang, H., \& Davison, W. 2004. Performance characteristics of suspended particulate reagentiminodiacetate as a binding agent for diffusive gradients in thin films. Anal. Chim. Acta 508(1): 41-51.

Williams, P.N., Santner, J., Larsen, M., Lehto, N.J., Oburger, E., Wenzel, W. \& Zhang, H. 2014. Localized flux maxima of arsenic, lead, and iron around root apices in flooded lowland rice. Environ. Sci. Technol. 48(15): 8498-8506.

Wu, C., Ye, Z., Shu, W., Zhu, Y. \& Wong, M. 2011. Arsenic accumulation and speciation in rice are affected by root aeration and variation of genotypes. J. Exp. Bot. 62(8): 2889-2898. 